\title{
Unión Europea: hacia una política exterior y de seguridad verdaderamente común
}

\author{
Joaquín Bordonado Fortuny \\ Capitán de Corbeta \\ Master en Estudios Estratégicos y Seguridad Internacional
}

\begin{abstract}
SuMARIo: 1. Introducción.-2. Razones para la comunitarización de la PESC. 2.1. El signo de los tiempos. 2.2. La necesidad de Europa de poder actuar de manera creíble sin la ayuda de los EE.UU.-3. Objetivos y prerrequisitos.-4. Los factores que intervienen en la postura de los Estados ante la unión en la PESC.-5. Factores endógenos. 5.1. Las diferencias en las culturas estratégicas. 5.2. Intergubernamentalismo frente a federalismo. 5.3. Nivel de acuerdo necesario para tomar decisiones por votación. - 6. El factor exógeno: atlantismo frente a eurocentrismo. La influencia de los EE.UU.-7. Se impone un cambio de paradigma. 7.1. La dificultad de Europa, en general, para razonar en clave planetaria. 7.2. Es difícil armonizar las políticas exteriores debido al peso de la tradición. 7.3. La potenciación de la Defensa europea. - 8. Herramientas a medida. Las coalitions of the willing llevadas a la permanencia. 8.1. La cooperación reforzada. 8.2. La cooperación estructurada permanente (CEP). -9. El peso de la opinión pública. 9.1. Una política exterior común a los 27 miembros de la UE. 9.2. Una política de seguridad y defensa común a los 27. 9.3. La UE debería constituirse en una federación de Estados-Nación. 9.4. Con qué velocidad está sucediendo la integración europea. 9.5. Con qué velocidad desearía Vd. que se produjera la integración europea. 9.6. Cuáles son los dos mayores problemas a los que se enfrenta la UE en la actualidad. 9.7. Me siento más seguro porque mi país es miembro de la UE. 9.8. Conclusiones generales de las estadísticas.-10. Conclusiones.
\end{abstract}

\section{INTRODUCCIÓN}

El objetivo inmediato de los pioneros de la construcción europea al finalizar la Segunda Guerra Mundial era hacer materialmente imposible otra guerra entre naciones europeas. Ese fue el fin declarado de la Declaración de Schuman (1951), por la que se proponía lo que se llamó la Comunidad Europea del Carbón y del Acero (CECA), cuya teoría subyacente era que ambos materiales son imprescindibles para la guerra moderna, y que si su producción y comercialización están mancomunados entre varios países se hace materialmente imposible una guerra entre ellos. Pero la visión de los padres fundadores iba más allá: por medio de la colaboración económica, sería posible conseguir gradualmente la integración política y la unificación de Europa, cosa que constituía su objetivo último (Economou y Metaxas 2011: 6). Los fundadores de la CECA, la CEE y la UEO utilizaron la integración económica, parafraseando a Clausewitz, como medio de promover sus intereses políticos por otros medios. 
Hoy, superado el riesgo de guerra europea, la lógica detrás de la construcción europea es ya la de la integración política. Europa ha sido el centro del mundo durante buena parte del último medio milenio, principalmente por la ausencia de otra región con niveles comparables de poder agregado ${ }^{1}$. Pero la proporción de Europa en la población y en el PIB mundiales disminuyen progresivamente, aunque la Unión Europea siga siendo aún el mayor mercado mundial. Las naciones de Europa, por sí solas, son demasiado pequeñas en poder agregado para poder seguir siendo relevantes a medio plazo. Para evitar caer en la irrelevancia, Europa no tiene otra opción que constituirse en una unión política.

La Unión Económica y Monetaria (UEM) es la plasmación más avanzada de la búsqueda de una unión política de Europa. Pese a conocer actualmente horas bajas, la UEM ha sido un éxito rotundo durante seis años. No pocos autores sostienen que la crisis que vive en la actualidad se debe precisamente a que las facultades mancomunadas no eran las suficientes, lo cual hacía imposible garantizar la coherencia de la política fiscal y económica a través de la Unión. Esta arquitectura funcionó bien en tiempos de bonanza, pero es insuficiente para tiempos de crisis. Por lo tanto, sólo será posible preservar la UEM (que, además de un paso en un proceso de mayor alcance, es ya un fin en sí misma) a base de profundizar en la compartición de soberanía. En resumen, la profundización en la unión política es la única posibilidad para escapar del deslizamiento hacia la irrelevancia de Europa en el mundo multipolar, y para salir de la crisis de la UEM.

La construcción europea ha estado siempre mediatizada (y lo está en particular desde que comenzó la transferencia de soberanía al nivel supranacional de manera significativa, es decir, desde la década de los 90 del siglo pasado) por la discusión sobre si el objetivo final debía ser una verdadera unión política de tipo federal, o bien solamente una unión de carácter intergubernamental, en la cual un organismo supranacional dictara ciertas reglas que limitaran de hecho, pero no de manera fundamental, las competencias de los Estados. La Unión Económica y Monetaria es un buen ejemplo. La adopción del euro como moneda común, y la transferencia de prerrogativas importantes (como la de decidir sobre la devaluación de la moneda) al Banco Central Europeo son características de la corriente federal. La inexistencia de un regulador fiscal común (que si nos atenemos a la lógica del funcionamiento debería ir unida a las anteriores) es exponente de la corriente intergubernamental.

Desde el Tratado de Maastricht, incluyendo el Tratado de Niza, la nonata Constitución Europea y el Tratado de Lisboa, las palabras y las declaraciones institucionales señalan un claro interés por avanzar en el camino federal. Sin embargo, una y otra vez, esas expectativas no llegan a materializarse.

${ }^{1}$ El poder agregado de un país se define como la suma de su tamaño físico, población, dotación de recursos, fuerza militar, estabilidad política y competencia. 
Es visible, pues, la falta de coherencia entre las declaraciones de intenciones de los Gobiernos de los países de la UE y la materialización de esas intenciones, en lo tocante a la profundización en la unión ${ }^{2}$. La razón es clara. El núcleo del Estado se articula principalmente en torno a la política fiscal, económica y monetaria, la política exterior y la defensa. La clave del proceso (lo que lo hace potente y a la vez complejo) es que cualquier avance en esta dirección, implica un retroceso equivalente en las atribuciones de cada uno de los Estados que formen parte del proyecto. Ningún Estado cederá atribuciones de su núcleo duro si las ventajas de hacerlo no están claras y los riesgos no se consideran aceptables (aunque de hecho la percepción de los riesgos y las oportunidades puede cambiar a través del tiempo precisamente por efecto del proceso en sí) $)^{3}$. La unión voluntaria en una entidad política común de naciones con características similares, pero diferentes, es un proceso muy complejo que nunca hasta ahora se había intentado en la era moderna. Las ventajas de conseguirla (o los riesgos de no hacerlo) están relativamente claros, y son la fuerza que impulsará a las naciones a adherirse a un proyecto tal. Las dificultades de orden práctico, así como los riesgos que es necesario aceptar, son las que impulsarán a la no adhesión. Todo ello mediatiza la actitud de cada nación en particular ante el proyecto según éste va tomando forma.

Por otro lado, como decíamos, se puede argüir que la propia existencia de este proceso puede servir de motivación a los Estados para alinear sus visiones y voluntades de manera que se avance en la unión ${ }^{4}$. Tanto las declaraciones institucionales, como los sucesivos Tratados de la Unión, impulsan a los países a efectuar cambios en su seno, de manera que a efectos prácticos eso supone ya una renuncia a la plena soberanía sobre el asunto de que se trate, puesto que ya existe el público compromiso de las intenciones. Si así sucediera, el ejemplo de unos debería actuar como acicate y como garantía en los demás, que a su vez serían más proclives a cambiar en la misma dirección.

En este trabajo vamos a examinar cuáles son las fuerzas que impulsan a los Gobiernos de la UE a profundizar en la unión política y cuáles son las que les impulsan a mantener su autonomía aun aceptando que Europa está abocada a la unión. Finalmente, exploraremos de qué maneras se puede,

${ }^{2}$ En un famoso artículo, Christopher Hill hablaba del capability-expectations gap (Hill 1993: 306).

${ }^{3}$ La teoría del institucionalismo liberal preconiza que eso es así a pesar de que la decisión de los Estados de cooperar entre sí se tome inicialmente según un cálculo basado en el interés nacional. Para una completa discusión de esta teoría, ver Keohane (1984) y Keohane (1999).

${ }^{4}$ La teoría del social-constructivismo sostiene que la pertenencia al grupo (es decir, la interacción con los demás miembros) cambia gradualmente la esencia de sus integrantes. La pertenencia al grupo no cambia sólo la percepción del interés nacional, sino la naturaleza de éste. Ver Wendt (1999). 
apoyándose en las primeras, tratar de allanar (u orillar) las dificultades que ofrecen las segundas.

Este estudio se centrará prioritariamente en la Política Exterior y de Seguridad Común (PESC) $)^{5}$ y en la Política Común de Seguridad y Defensa (PCSD) como manifestación particular de la PESC, en cuanto aspectos parciales de una unión política que incluye muchos otros órdenes de la actividad del Estado. En el curso de este trabajo trataremos de delimitar también qué es lo que buscamos en realidad cuando hablamos de la evolución de la PESC para ser verdaderamente común. Veremos también en qué aspectos no lo es (o sería posible avanzar), y dónde se podría mejorar con mayor garantía de éxito.

\section{RAZONES PARA LA COMUNITARIZACIÓN DE LA PESC}

La delegación de soberanía en las políticas exterior y de seguridad de un Estado parece casi una contradicción en términos. Sin embargo, hay razones para pensar que este paso radical no es sólo aconsejable, sino quizás imprescindible.

\subsection{El signo de los tiempos}

Tal como ha señalado la propia Unión Europea, ningún país es capaz por sí solo de enfrentarse a los complejos problemas de hoy (Unión Europea 2003: 1, citado por Giegerich 2006: 65). Tampoco las naciones europeas, que por muy desarrolladas y prósperas que sean ya no tienen el tamaño para influir significativamente por sí mismas en cualquier asunto de su elección. Sin embargo, la conveniencia (o la necesidad) de dicha capacidad de influencia siguen estando presentes, ahora como en el pasado. La solución lógica es sumar peso específico entre ellas al objeto de alcanzar una masa suficiente como para que sí pueda influir donde interese.

La coordinación entre los países de la UE para abordar juntos dichos problemas alcanza variados estados de integración, que en el caso particular de la PCSD se ha definido como intergubernamentalismo intensivo (Wallace 2000: 33-35, citado por Giegerich 2006: 14). Cada país mantiene su soberanía, pero el nivel de coordinación mutua es muy elevado.

La PESC en general se basa en la cooperación avanzada. Esto no es incompatible con la acción exterior de las naciones por sí mismas, y de hecho una coalition of the willing ${ }^{6}$ en sentido usual no deja de ser una suma de decisiones nacionales. Pero es obvio que la capacidad de influencia del grupo, y la imagen que dé al exterior, sólo alcanzarán su máximo potencial en una

${ }^{5}$ Los antecedentes de la PESC están muy detalladamente explicados en García Pérez (2003).

${ }^{6}$ Este término, que se podría traducir por coalición de voluntarios, se utiliza en general para designar una coalición que tiene un objetivo concreto y limitado en el tiempo. En este trabajo, salvo que se indique otra cosa, lo usaremos para designar una coalición con vocación de permanencia. 
verdadera unión de tipo federal donde el órgano de decisión sea uno solo y no una coordinación de varios, por buena que sea.

\subsection{La necesidad de Europa de poder actuar de manera creíble sin la ayuda de los EE.UU.}

Como trataremos de explicar a continuación, la UE precisa de capacidad de autonomía con respecto a los EE.UU. La UE debe ser capaz de actuar por sí sola donde lo considere necesario y los EE.UU. (o la OTAN) no quieran, o no puedan, implicarse.

Los EE.UU., por su parte, tienden en general a ver en el fortalecimiento de la PESC y de la capacidad de la UE de actuar con autonomía en la esfera internacional un riesgo para su peso relativo en el sistema euroatlántico ${ }^{7}$. No deja de ser una postura lógica y legítima. Sin embargo, por las mismas razones del párrafo anterior, pero aplicadas en sentido contrario, deberían ver en ello también una oportunidad, y en el fortalecimiento de Europa una herramienta que les abre posibilidades en un mundo en el que el mantenimiento indefinido de su nivel de influencia actual es, cuando menos, incierto. También esto lo veremos más adelante.

\section{OBJETIVOS Y PRERREQUISITOS}

La cuestión general de la que estamos tratando es la profundización en el carácter común de la PESC, donde el límite teórico es la comunitarización absoluta, es decir, la gestión de la PESC directamente por un organismo supranacional autónomo. Desde la perspectiva de los Gobiernos, su actitud sobre este particular estará formada por su percepción sobre los objetivos que se espera conseguir y los riesgos que se está dispuesto a asumir. Este cálculo debe hacerse teniendo en cuenta que la profundización en la PESC en cualquiera de sus facetas presenta oportunidades y riesgos, pero también la decisión consciente de no profundizar en dichas facetas presenta oportunidades y riesgos, que serán en general pero no necesariamente simétricos a los anteriores. En general, los objetivos que se pretende conseguir con la PESC y la PCSD son los siguientes:

- Dar a la UE un instrumento para alcanzar el peso internacional que le corresponde.

- Hacer avanzar el proceso de integración europea.

- Sentar las bases para que la UE acabe teniendo una verdadera política exterior común.

- Coordinar las políticas exteriores de los países de la UE, mientras no se consiga lo anterior.

- Proporcionar un marco para el ajuste de la influencia política relativa dentro de la UE.

${ }^{7}$ Vilanova y Baqués (2008) y Hunter (2002) tratan esta afirmación en profundidad. 
- Proporcionar a los europeos una seguridad adicional de modo que dispongan de una cierta fuerza militar para el caso de que la OTAN (es decir, en la práctica, los EE.UU.) decidiera no implicarse.

- Reaccionar a las constantes quejas norteamericanas sobre el reparto de cargas (burden sharing) en la OTAN.

- Proporcionar un incentivo político añadido para la modernización de las fuerzas militares europeas y asegurar que, dentro de lo posible, sigan siendo tecnológicamente compatibles (interoperables) con las norteamericanas, cuya modernización es más rápida.

- Proporcionar a Europa mayor influencia en la OTAN.

- Apuntalar el proceso de ampliación en Europa Central.

- Contribuir a la consolidación de la industria de Defensa europea, proporcionar una demanda añadida de equipamientos militares, y crear un marco político para competir y cooperar con sus contrapartes norteamericanos.

En lo que la PESC toca a la construcción europea, el objetivo último es la federalización de la acción exterior de la Unión. Aceptamos que es un objetivo más bien a largo plazo. Además, la unión resultante no tendría por qué ser unitaria: en muchas áreas podría respetarse la idiosincrasia de los Estados, y aun en otras eso daría mucho mejor resultado. Como veremos, el intergubernamentalismo pudiera incluso demostrarse una solución más eficaz para la gestión de crisis. En cualquier caso, en un asunto tan delicado sólo se debe cambiar de paradigma cuando esté claro que el nuevo ofrecerá mejores resultados que el antiguo.Y de momento el antiguo funciona razonablemente bien.

Para avanzar en la federalización es necesario primeramente armonizar visiones sobre la mayor cantidad posible de asuntos, mediante la generación de agendas comunes a través de aproximaciones de mínimos compartidos. La voluntad de converger y de aproximar debería verse favorecida por razones que luego veremos ${ }^{8}$, que dan razón de ser al esfuerzo por la comunitarización de la política exterior (y de las demás).

\section{LOS FACTORES QUE INTERVIENEN EN LA POSTURA DE LOS ESTADOS ANTE LA UNIÓN EN LA PESC}

Como ya hemos dicho, la unión de Europa en todos los órdenes estaba ya en la agenda de los padres fundadores como objetivo último. En lo tocante a la política exterior, los países de la Unión Europea han publicado repetidamente, y en documentos del máximo nivel, su convencimiento de que la convergencia en esta materia, con vistas a una eventual política exterior común, redundarían en beneficio de todos ellos y de la Unión en su conjunto9. Sin

${ }^{8}$ En esencia, la pérdida de influencia de Europa en particular y del área euroatlántica en general en los asuntos mundiales. Vid. epígrafe 6. infra.

9 La última manifestación importante de este pensamiento se encuentra en el Tratado de la Unión Europea: entre otros, en el Preámbulo, en los Art. 24 y 32. Pero el mismo espíritu se encuentra ya en el Tratado de Maastricht. 
embargo, todos ellos caen por debajo de sus propias expectativas y de los objetivos que se marcan a sí mismos en lo referente a la implementación de esta convergencia. No sólo eso, sino que además aparecen diferencias significativas de unos Gobiernos a otros en cuanto a su grado de avance en general, así como en cuanto al grado de avance en ciertas áreas en particular. Se observa, pues, una falta de coherencia entre lo que los Gobiernos acuerdan cambiar (con un compromiso implícito de cada uno de ellos), por un lado, y lo que cada Gobierno acaba efectivamente cambiando (Giegerich 2006: 10). Cosa hasta cierto punto esperable, puesto que hacer declaraciones es relativamente sencillo, pero pasar de las palabras a los hechos encierra mayor dificultad. Esto es así tanto más cuanto más compleja y radical sea la empresa que se quiere hacer realidad. Y la construcción europea, ciertamente, tiene mucho de compleja (puesto que son muchos los aspectos que se deben coordinar), $\mathrm{y}$ de radical, puesto que el proceso implica la renuncia voluntaria por los Estados a su soberanía, o parte de ella, en cuestiones que afectan a la propia esencia del Estado.

Se puede decir en general que, en ausencia de una amenaza exterior clara e inminente, la política exterior de los Gobiernos está influida en una gran proporción por factores de política nacional. Esto sucede también para el caso particular de la PESC. Pero es razonable pensar que también el nivel europeo tendrá una cierta influencia en las políticas nacionales. Giegerich explica la mecánica de manera muy clara: La UE actúa como nivel intermedio entre el nacional y el internacional. La PESC crea metas, aspiraciones y capacidades tanto institucionales como operativas para responder [a las presiones que crea la política internacional] por medio del marco que ofrece la UE. Por lo tanto, la PESC tiene una lógica inherente bien definida, y que puede ser comparada con las culturas estratégicas nacionales. No se produce por sí misma una cultura estratégica común en el sentido de una visión que todos los países comparten, pero sí queda definido un marco de referencia, influido significativamente por la evolución externa, mediante el cual se pueden medir las respuestas de los Gobiernos (Giegerich 2006: 64).

Vamos a ver a continuación de qué manera influyen en la actitud de cada país la cultura estratégica y la mentalidad. También analizaremos la única influencia exógena digna de mención: la de los EE.UU.

\section{FACTORES ENDÓGENOS}

\subsection{Las diferencias en las culturas estratégicas}

Se puede definir la cultura estratégica como la actitud de un Estado en relación con el recurso al uso de la fuerza como instrumento político ${ }^{10}$. En general, puede decirse que conviven en el seno de la UE tres culturas estraté-

${ }^{10}$ Para un excelente análisis de los matices del término, ver Giegerich 2006: 36-40. 
gicas diferentes ${ }^{11}$ : a) Asertiva, dada a la proyección y relativamente cómoda con el uso de la fuerza, que se da entre otros en Gran Bretaña, Francia, o los Países Bajos; b) Retraída, dada al comedimiento y poco proclive al uso de la fuerza: Alemania, Italia, España, Bélgica o Portugal, entre otros; c) Neutral (Irlanda, Suecia, Finlandia, Malta o Austria). Es un tipo específico de retraimiento, si se quiere, caracterizado por una mayor intensidad.

\subsection{Intergubernamentalismo frente a federalismo}

Una de las diferencias más profundas en cuanto al futuro de la unión política en la UE se da en torno al régimen de distribución de soberanía que se quiere conseguir. Moravcsik (1998: 67, citado por Wagner 2003: 581) explica la disyuntiva con claridad: la soberanía es compartida cuando los Gobiernos acuerdan adoptar las decisiones futuras mediante votación por sistemas diferentes de la unanimidad. En cambio, la soberanía es delegada cuando las instituciones supranacionales pueden tomar ciertas decisiones de manera autónoma, sin que deban intervenir una votación o una posibilidad de veto.

Las dos corrientes de pensamiento son las siguientes (Dullien y Torreblanca 2012: 5-6): por un lado, la minimalista, que preconiza el intergubernamentalismo, en la que los Estados son los depositarios últimos de la legitimidad y la democracia, y el traspaso de soberanía que implica la unión política haría necesario paralelamente que se reforzara la presencia de los Estados en el proceso de la decisión en la Unión; por otro, la maximalista, que propone el federalismo, el refuerzo de la capacidad política y la legitimidad democrática de las instituciones europeas ya existentes, en especial el Parlamento y la Comisión. En suma, el objetivo es replicar al nivel de la Unión el sistema nacional de Gobierno y oposición, izquierda y derecha, defensor y aspirante.

Por si esta disyuntiva no fuera suficientemente compleja, Dullien y Torreblanca (2012: 3) arguyen que, complementariamente al debate sobre el carácter de la unión, se deben producir otros dos:

- entre un Gobierno europeo basado en la reglamentación (que daría directrices generales con objeto de hacer converger las políticas nacionales a base de limitar el campo de acción de los Gobiernos) o uno con poderes discrecionales propios (que serían necesarios dada la complejidad e interdependencia de los asuntos públicos).

- entre la representatividad ${ }^{12}$ de las instituciones europeas directa o indirecta. En general, las propuestas van desde la elección indirecta de

${ }^{11}$ El reparto de países por categorías se puede encontrar por ejemplo en Vilanova y Baqués 2008: 60 y ss.

12 Además de la legitimación por representatividad, todo Gobierno, y también la UE, busca la legitimidad de resultados (que el público perciba que sus políticas dan el resultado buscado). Es lo que en inglés se denomina, respectivamente, legitimidades de input y output. Hay quien para el caso particular de la UE señala un nivel adicional de legitimidad, de throughput, que podríamos traducir por de proceso, basada en el grado de eficacia, responsabilidad (accountability), transparencia e inclusividad de los procesos. Sobre el 
la Comisión y el Parlamento, como sucede en la actualidad, hasta la elección directa del Presidente de la Comisión, que elegiría a su vez a sus miembros, de tal manera que la Comisión se conformara, en líneas generales, a la visión de los partidos que la apoyan en el Parlamento. Que, a su vez, estaría dotado de más amplias prerrogativas.

La idea subyacente a estas dos disyuntivas adicionales es que, conforme la soberanía va siendo delegada para cuestiones importantes ${ }^{13}$ (de momento, las monetarias y, en parte, la acción exterior; en un futuro próximo, quizás las fiscales y/o bancarias) la Unión va incrementando su carácter federal y la Comisión aumentando sus prerrogativas. Estos cambios afectarán de tal manera a las vidas de los ciudadanos, que gradualmente las instituciones supranacionales estarán necesitadas de mayor legitimidad democrática so pena de ver sus decisiones contestadas, en virtud del conocido principio (aplicado en sentido amplio) de no taxation without representation.

\subsection{Nivel de acuerdo necesario para tomar decisiones por votación}

Otra diferencia de criterio existente, y subsidiaria a la anterior, concierne al nivel de acuerdo necesario para adoptar decisiones por votación. Mientras en algunas cuestiones importantes la soberanía esté compartida (según el criterio de Moravcsik), habrá cuestiones que se deban decidir mediante el voto de cada nación en un órgano colegiado. En particular, y en la actualidad, eso es así para todas las cuestiones relacionadas con la acción exterior, entre ellas las relacionadas con la gestión de crisis y la acción militar, que deben tomarse por unanimidad ${ }^{14}$.

Tal como argumenta Wagner, y por las razones señaladas más arriba (como sucede en la OTAN), el cambio de mentalidad necesario para delegar soberanía en cuestiones de respuesta a crisis está hoy en día muy lejano y, además, no está claro que vaya a mejorar las prestaciones del sistema (Wagner 2003). Otros aspectos de la acción exterior, sin embargo, sí que se adaptan más fácilmente a la delegación en una institución supranacional. Éste es, en realidad, el cambio que está operando el Servicio Europeo de Acción Exterior (SEAE) en no pocos aspectos(Priego 2013: 7-22), como la Política de Vecindad Europea, las relaciones con socios estratégicos (EE.UU., Federación Rusa, China, Brasil, India, Japón, México, Canadá y Corea del Sur), la gestión de los desafíos internacionales del momento (las revueltas árabes,

importante concepto de legitimidad y sus implicaciones, ver Schmidt 2013 y Giegerich y Gross 2006.

13 No se trata obviamente de una disyuntiva categórica: no se puede pasar directamente del intergubernamentalismo puro a la federación pura, sino que se va haciendo por asuntos, y dentro de ellos, por etapas, paso a paso.

${ }^{14}$ Los casos exactos en que se aplica cada método de votación están recogidos en el Tratado de la Unión Europea (TUE) y en el Tratado de Funcionamiento de la Unión Europea (TFUE). 
el proceso de paz árabe-israelí, el programa nuclear iraní, la situación en el Cuerno de África o los sucesos en Malí).

\section{EL FACTOR EXÓGENO: ATLANTISMO FRENTE A EURO- CENTRISMO. LA INFLUENCIA DE LOS EE.UU.}

Se puede decir que durante la guerra fría, las relaciones estratégicas entre las dos orillas del Atlántico se basaban grosso modo en un intercambio por el que Europa recibía seguridad a cambio de aceptar el dominio de la visión norteamericana en el conjunto de la OTAN, y los EE.UU. proporcionaban seguridad, y en contrapartida ejercían un cierto dominio sobre el modo en que se articulaba este intercambio. El desarrollo en la UE de una política exterior y de seguridad común (y propia, en el sentido de no necesariamente coincidente con la visión norteamericana) ha suscitado recelos en los EE.UU., puesto que parecía cuestionar ese acuerdo tácito. Los EE.UU. tienden a ver el nacimiento de la PESC como un juego de suma cero, en el cual el incremento del peso específico internacional de Europa iría en detrimento de la fortaleza del llamado vínculo trasatlántico, de los intereses de los EE.UU., y entre ellos, de la cohesión y eficacia de la OTAN. En efecto, la existencia de la PESC hace plausible que Europa tenga la posibilidad física de actuar en la escena internacional al margen de los EE.UU. (al contrario que sus miembros, que por separado son demasiado pequeños para hacerlo por sí mismos). Al no existir hasta ahora esta posibilidad, los EE.UU. perciben que su influencia sobre Europa disminuye, y además, que se abre la posibilidad de que Europa actúe en alguna ocasión en la escena internacional en un sentido que los EE.UU. no compartan.

Es legítima la preocupación de los EE.UU. Efectivamente, el surgimiento y eventual maduración de la PESC introducen esta posibilidad, que podría ser, como vemos, contraria a los intereses de los EE.UU. Desde este punto de vista, parece que la PESC traerá como consecuencia el debilitamiento del «vínculo trasatlántico». A continuación trataremos de mostrar que no necesariamente tiene que ser así, y además que, bien al contrario, los EE.UU. tienen motivos para ver con satisfacción este proceso.

La posición norteamericana se ha basado en general en el concepto de la OTAN primero. Para los EE.UU. (y los atlantistas), las dudas proceden en parte de la tensión inherente a la voluntad de una PCSD y una Europa fuertes, y a la vez la aceptación clara de la primacía de la OTAN como herramienta de gestión de crisis. En opinión de los EE.UU., la OTAN debería tener el right of first refusal, según el cual la UE sólo lideraría una operación si la OTAN hubiera decidido primero no implicarse. (Hunter 2002: 146). En cualquier caso, el Art. 42.2 del TUE obliga expresamente a que la PCSD respete las obligaciones derivadas del Tratado del Atlántico Norte para determinados Estados miembros (...) y sea compatible con la política común de seguridad $y$ de defensa establecida en dicho marco. Más aún, el 42.7 instituye la defensa mutua al estilo del Art. 5 de la Carta del Atlántico Norte, pero advierte de 
que los compromisos y la cooperación en este ámbito seguirán ajustándose a los compromisos adquiridos en el marco de la Organización del Tratado del Atlántico Norte, que seguirá siendo, para los Estados miembros que forman parte de la misma, el fundamento de su defensa colectiva y el organismo de ejecución de ésta. Parece, pues, que este asunto ha sido regulado de manera que queden satisfechas las suspicacias de la corriente atlantista.

Otro eje de la posición norteamericana ha consistido en favorecer el crecimiento de la identidad de defensa europea de tal modo que se evitara la duplicación de capacidades entre la OTAN y la UE en la transformación ${ }^{15}$ de las Fuerzas Armadas de los países europeos. Pero, como se ha demostrado mientras han estado activas las guerras de Irak y Afganistán, es concebible un momento en el que los EE.UU. se vean imposibilitados de acudir con la entidad suficiente a donde sea necesario para ellos, para Europa o para ambos. Lo cual aconseja que Europa duplique ciertas capacidades aunque sea a pequeña escala, al objeto de asegurar una mínima entidad autónoma de la capacidad que pueda ser necesaria en un momento dado, para poder suplir o complementar la disponibilidad norteamericana. Y esa conclusión vale tanto desde el punto de vista europeo como desde el norteamericano.

La hegemonía mundial de los EE.UU. se sustenta en el tamaño de su economía y en el tamaño y nivel de sus Fuerzas Armadas. Sin embargo, este liderazgo global se mantiene a base de un déficit público constante, y que hace que la deuda pública total se sitúe en la actualidad en el 105\% del Producto Nacional Bruto, y aumentando a un ritmo elevado. ${ }^{16}$ Como indicación, este porcentaje era del $90 \%$ en 2011. Este estado de cosas supone un riesgo estratégico, que se podría materializar en caso de acontecimientos adversos de importancia global, como, por citar una posibilidad, una crisis motivada por la inestabilidad del flujo de crudo a través del Estrecho de Ormuz. Y aun en ausencia de un acontecimiento global que desencadene una crisis similar para el caso de los EE.UU., parece difícil que se pueda mantener indefinidamente tanto el déficit como el ritmo de gasto que lo genera. Hay margen para disminuir este último, desde luego: el gasto en Defensa de los EE.UU. era en 2009 el 43\% del total mundial (Economou y Metaxas 2011: 22) y bajó del 40\% en 2012 por primera vez desde el fin de la Guerra Fría, debido a un descenso del $6 \%$ en términos reales ${ }^{17}$, principalmente por la disminución en los gastos de guerra. Pero parece plausible que a medio plazo, y por la necesidad de cuadrar las cuentas, los EE.UU. se vean obligados a disminuir el gasto en Defensa, y con ello su papel de potencia global. En cualquier caso, (Kennedy 1988)

15 Transformación de unas FAS propias de la Guerra Fría (tamaño, potencia de fuego, unidades blindadas) a otras más orientadas a las necesidades actuales (carácter expedicionario, interoperabilidad, conexión en red).

${ }^{16} \mathrm{http} / / /$ research.stlouisfed.org/fred2/series/GFDEGDQ188S Consultado el 11 de junio de 2013.

${ }^{17}$ http://www.sipri.org/media/pressreleases/2013/milex_launch. Consultado el 27 de mayo de 2013. 
las potencias dominantes a través de la Historia sólo han podido mantener su hegemonía mientras su economía pudo sostener los gastos necesarios. Kennedy cita expresamente los casos del Imperio Otomano, la Francia napoleónica y el Imperio español de los Habsburgo. La Historia (Economou y Metaxas 2011: 31) demuestra que la hegemonía no es un monopolio natural.

Es un concepto manido el desplazamiento del centro de poder del mundo hacia Asia, en particular, y el crecimiento económico significativo de una buena parte de África, así como Brasil e incluso México y, como consecuencia, la pérdida de peso específico de los EE.UU. y de Europa en el sistema internacional. 2012 será recordado como el punto de inflexión en que la producción de las economías emergentes superó a la de los viejos países industrializados (Fabry 2013: 6).

Todo ello indica que, a pesar de incurrir en gastos difícilmente sostenibles, el predominio mundial de los EE.UU. que les daba la posibilidad de intervenir solos donde les pareciera conveniente es más cosa del pasado que del futuro. En resumidas cuentas, el acuerdo tácito que sustentaba el reparto de tareas en la comunidad euroatlántica está perdiendo rápidamente sentido para ambas partes. La alternativa abierta por la PESC se sustenta en la idea de que, si Europa fuera autónoma, los EE.UU. ya no tendrían asegurada la influencia en las políticas de su socio, pero a cambio tendrían un socio potente capaz de quitarles parte del peso de ser potencia global. Si, en el futuro, van a necesitar apoyo de otros, parece de lógica inmediata el recurso a la UE para llenar en parte esa función. De hecho, si bien es cierto que una mayor autonomía europea posibilitaría en cierto modo contrariar los deseos de Washington, no debería implicar necesariamente que eso sucediera, entre otras cosas porque en la mayoría de las situaciones posibles los intereses de ambos lados del Atlántico serían coincidentes. Y en todo caso, cualquier otra potencia compartirá con los EE.UU. muchos menos valores y, sobre todo, intereses. La conclusión es que, más que otra cosa, los EE.UU. y Europa están llamados a ser complementarios.

En este sentido, los EE.UU. son conscientes de que una Europa fuerte tiene para ellos más ventajas que inconvenientes, como ya advirtieron Obama con ocasión de la polémica euroescéptica en el Partido Conservador británico en mayo de 2013 («el Reino Unido debería arreglar una relación muy importante antes de romperla por completo»), y su subsecretario de Estado, Philip Gordon ( «Si Londres abandona la UE o rebaja su papel desempeñado en el bloque, habrá consecuencias negativas en sus relaciones con EEUU») ${ }^{18}$. Pecaría de optimista quien viera en estas declaraciones un cambio de actitud en cuanto a la tradicional prevención de los EE.UU. con respecto a la PESC, pero sí son una señal de que algo está cambiando y, lo más importante, hay razones claras que apuntan a un cambio en esa dirección. Y sobre las cuales

${ }_{18}$ Diario El Mundo, ed. Madrid, 20 de mayo de 2013, pg. 32. 
se puede cimentar un esfuerzo diplomático europeo dirigido precisamente a cambiar esa percepción negativa en el socio ultramarino.

Por otra parte, la potenciación de la identidad de defensa europea (y la constatación de la necesidad de una cierta autonomía europea) pudieran servir como catalizador para que Europa se decidiera a invertir en Defensa lo que le corresponde. En cualquier caso, si finalmente Europa llegara a asumir su parte en el burden sharing del gasto de Defensa en la OTAN, pasaría a tener un grado de autonomía significativamente mayor que el actual. Dicho de otro modo, la inversión en Defensa, la consecución de capacidades militares y la autonomía con que Europa podría ejercer su política exterior con respecto a los EE.UU. son tres magnitudes directamente proporcionales entre sí, que se refuerzan mutuamente.

\section{SE IMPONE UN CAMBIO DE PARADIGMA}

La realización plena del potencial beneficio que se derivara de la comunitarización de la PESC (y en particular de la PCSD) precisa de un cambio de paradigma en la UE (a niveles nacional y de opinión pública) en ciertos aspectos, entre los que destacan los siguientes: La dificultad de Europa, en general, para razonar en clave planetaria, la dificultad de armonizar las políticas exteriores, debido al peso de la tradición y la potenciación de la defensa europea.

\subsection{La dificultad de Europa, en general, para razonar en clave planetaria}

La consecuencia es una mala definición de la política exterior tanto a nivel nacional como de la UE, entre la actitud reactiva ante lo que hagan los EE.UU. y la atrofia diplomática (Vilanova y Baqués 2008: 53). La ventaja de la postura europea es que es más comedida que la norteamericana. Pero en cualquier caso el mayor defecto de Europa es la general indefinición de las políticas exteriores nacionales y, como consecuencia, de la PESC. Salvo, lógicamente, en los países de cultura estratégica asertiva. Lo cual introduce una dificultad en cierto modo simétrica a la primera.

\subsection{Es difícil armonizar las políticas exteriores, debido al peso de la tra- dición}

En este sentido, es interesante notar cómo la PESC se ha fortalecido significativamente cada vez que el Reino Unido ha aceptado posturas de corte europeísta en oposición a su tendencia atlantista (como botón de muestra, lo conseguido en la cumbre de Saint Malo, donde se resolvió conseguir para la UE una capacidad autónoma de acción, apoyada sobre fuerzas militares creíbles, con los medios precisos, y dispuestas a ser utilizadas en respuesta a crisis internacionales).

Parece que el motivo profundo del Reino Unido en esa ocasión tuvo que ver con la entonces candente crisis de los Balcanes: Europa había sido inca- 
paz de hacer nada, y los EE.UU. necesitaban que fuera capaz de gestionar al menos lo que sucediera cerca de ella para poder delegar y no tener que ocuparse de absolutamente todo. Pero en ese momento los EE.UU. querían una Europa fuerte... siempre que aceptara la visión norteamericana de las cosas. Una Europa demasiado autónoma no convenía. Cambiar eso también necesita un cambio de paradigma, que hemos visto que ya se está produciendo.

Otros habituales atlantistas (Vilanova y Baqués 2008: 61 ss) son Portugal, los Países Bajos, Italia ${ }^{19}$, Dinamarca, y los antiguos países de la órbita soviética (cada vez más autónomos, por otra parte). Pero como hemos visto Francia y Alemania, los dos líderes de la corriente europeísta (a la que pertenecen también Bélgica, España o Luxemburgo), tienen culturas estratégicas opuestas, y por tanto difícilmente conciliables. Además, Francia tiene un cierto prurito tendente a oponerse a lo que venga de Washington (lo cual, si bien se mira, no deja de ser una manera de dejarse mediatizar por aquél de cuya influencia se pretende escapar). La historia de Francia es la adaptación tardía a la dura realidad: La historia de las relaciones internacionales de Francia desde 1919 ha sido el empeño de los hechos objetivos de la vida internacional por no seguir obedientemente la imagen gloriosa (Chuter 1996: 26, citado por Giegerich 2006: 76). La noción de excepcionalismo permea toda la vida política francesa (Giegerich 2006: 77 ss). En este sentido, Francia tiende, aunque por razones diferentes, a compartir la visión norteamericana según la cual una Europa unida es buena en la medida en que se conforme a las expectativas francesas.

Otro punto de desacuerdo es el introducido por los paradigmas de los Estados neutrales, que en la mayoría de los casos (con la notoria excepción, quizás, de Austria) son celosos de su neutralidad y por tanto reacios a apoyar iniciativas que puedan comprometerla, aunque sean colectivas.

Ya hemos visto, sin embargo, cómo por efecto de la PESC la convergencia de las políticas exteriores de los países de la UE ha experimentado avances significativos en ámbitos importantes (Priego 2013).

\subsection{La potenciación de la Defensa europea}

Una PESC verdaderamente autónoma necesita apoyarse en un elemento militar creíble, cosa que la UE en su conjunto está muy lejos de poseer. De hecho, es evidente que aunque esto sea un hecho conocido los países de la UE son remisos a gastar en Defensa lo que sería necesario para lograr lo que indudablemente desearían lograr. Por lo tanto, por la vía de los hechos, Europa puede ser autónoma, llegado el caso, sólo en situaciones de baja intensidad o que necesiten fuerzas de reducida entidad. Se constata en los últimos años que, ante la disyuntiva entre manejar y enfrentarse a los conflictos,

${ }^{19}$ Otros (Alecu de Flers 2008: 7) incluyen a Italia entre los europeístas. Nosotros nos decantamos por la opinión de Vilanova y Baqués. 
Europa siempre opta por lo primero. Es más, ni siquiera se plantea la opción de optar por lo segundo, por irrealizable.

Para poder ser verdaderamente autónoma, Europa necesitará:

a. Un elemento militar provisto de las capacidades que sean necesarias para cada ocasión.

Obviamente las capacidades necesarias dependen del objetivo, envergadura, localización y duración de la misión. Los países de la UE combinan entre sí Fuerzas Armadas orientadas cada una a capacidades diferentes. En teoría, la entidad de la fuerza que sería posible utilizar es la suma de todo lo que posean los países de la UE relevante a la misión de que se trate. Pero en algunas capacidades que se muestran muy frecuentemente necesarias en el mundo actual, esa suma sigue siendo limitada. Por esta razón, la autonomía europea pasa por aceptar la idea de que para ser capaces de intervenir sola donde se considere necesario, necesita potenciar ciertas capacidades (en general ya identificadas desde hace tiempo), es decir, necesita aumentar la entidad y/o la eficiencia de su gasto militar (Techau 2013, Simón 2013), con lo que eso implica de cambio de mentalidad en la opinión pública de la mayoría de países. Si no estamos dispuestos a eso, entonces la UE deberá reevaluar para qué tipo de situaciones quiere ser autónoma, y rebajar su nivel de ambición declarado. Otra cosa es el nivel de ambición hasta ahora demostrado: de momento, el patrón de comportamiento de la UE se corresponde con el de una pequeña potencia y no con una vocación de influencia en la escena internacional (Toje 2011: 48-55).

En cualquier caso, el presupuesto militar agregado de la UE es ciertamente notable, siendo claramente superior al ruso y al chino. Sin embargo, la percepción por todos los actores (incluidos estos tres) es que el poder militar de la UE es mucho menor, en términos comparativos, que lo que esos números hacen pensar. Quizás el problema no es que los europeos gasten poco, sino que lo que gastan les cunde menos (Andréani et al. 2001: 56, citado por Vilanova y Baqués 2006: 77). Hace años ya que se está intentando aumentar la eficiencia del gasto militar europeo, lo cual es la razón de ser de la Agencia de Defensa Europea (EDA), mediante iniciativas como la identificación de sinergias, la generación de economías de escala y la compartición de programas de I+D.

b. Estructuras capaces de decidir que es necesaria una actuación, en qué sentido, y con qué objetivos y limitaciones.

Por el momento, la opción intergubernamental para la gestión de crisis ha demostrado ser relativamente eficaz, y no está claro que una federalización de esta actividad vaya a dar resultados mejores que los actuales (Wagner 2003). Pero sí es necesario, en aras de la eficacia a largo plazo, efectuar planeamientos de contingencia para decidir a qué situaciones la UE quiere poder responder de manera autónoma. Este planeamiento a medio-largo plazo exige un nivel tan elevado de comunión de prioridades e intereses entre los actores, que precisa, idealmente, de una estructura que supere el intergu- 
bernamentalismo y tienda a la comunidad. Esto es parte de los cometidos del SEAE, que ha conseguido que la acción exterior de la UE mejore en coherencia entre las diferentes voces y la voz del Alto Representante, fomentar la colaboración institucional en política exterior, y dotar a la PESC de un componente de continuidad a través del tiempo (Priego 2013: 5-7). Parece lógico pensar que es probable que, con el tiempo, este proceso se auto-realimente, actuando también como un motor de la integración.

Para el resto del planeamiento y ejecución (nivel operacional e inferiores) ya existe una estructura dedicada: el Estado Mayor de la UE. Que, en todo caso, podría necesitar aumentar su tamaño, pero la organización que le permita realizar dichas tareas existe ya.

\section{HERRAMIENTAS A MEDIDA. LAS COALITIONS OF THE WI- LLING LLEVADAS A LA PERMANENCIA}

Más allá de la retórica del TUE, el estado actual de la PESC es que todos los Estados miembros se comprometen a un intergubernamentalismo lo más estrecho posible, nada más ${ }^{20}$. Lo cual sirvió en su momento para convencer a los Estados más celosos de su soberanía en este campo. Los frutos de este marco de actuación han sido muchos, como ya hemos visto.

Existen dos procedimientos previstos para poder profundizar en la integración: la Cooperación Reforzada (CR) y la Cooperación Estructurada Permanente (CEP). Ambos se basan en aceptar que la profundización en la unión se lleve a cabo entre los países mejor dispuestos a ello, y no en todos a la vez obligatoriamente, lo cual como es obvio mejora las expectativas de llegar a algo concreto y que valga la pena. Hacerlo así introduce el riesgo de crear una fractura y, lo que es peor, de institucionalizarla, creando un foso psicológico que ya sería muy difícil salvar. Sin embargo, también podría suceder que la existencia (y, en su caso, el éxito, por limitado que fuera) de esa cooperación reforzada, anime a otras naciones de la UE a sumarse a ella.

Vamos a discutir la adecuación de cada uno de estos dos métodos al objetivo de establecer una Política Exterior y de Seguridad común.

\subsection{La cooperación reforzada}

El Art. 20.2 del TUE consagra el instrumento de la cooperación reforzada, explícitamente, para reforzar el proceso de integración. ${ }^{21}$ El procedimiento está descrito en los Art. 328 y siguientes del TFUE: Debe iniciar el procedimiento un grupo de al menos nueve Estados Miembros, y debe ser una solución de último recurso cuando sea patente que la finalidad persegui-

${ }^{20}$ De hecho, el Art. 42.2 regula expresamente que la PCSD no afectará al carácter especifico de la política de seguridad y de defensa de determinados Estados miembros.

${ }^{21}$ A partir del Tratado de Lisboa, todas las cuestiones pueden ser objeto de cooperación reforzada, incluidas las de política exterior y seguridad y las relacionadas con el ámbito militar y la defensa. 
da por dicha cooperación reforzada no puede ser alcanzada en un plazo razonable por la Unión en su conjunto. Puesto que es patente que éste es el caso de la delegación de soberanía en un ente supranacional en lo que respecta a la PESC, esa condición se cumple. En cuanto al mínimo de nueve Estados, la historia de la construcción europea muestra que debería haber bastantes más. Las dos primeras estadísticas del punto anterior muestran que también las opiniones públicas de un buen número de países apoyarían la idea.

En cuanto al objetivo a que se refiere el Art. 329.1 del TFUE, es según hemos dicho la delegación de soberanía en un ente supranacional. A la medida de este objetivo (que es el verdadero avance cualitativo que se quiere conseguir) debe diseñarse el resto de la CR. En cuanto al ámbito de aplicación al que se refiere el Art. 329.1 del TFUE, es en última instancia la totalidad de la PESC. Para facilitar la puesta en funcionamiento de la CR, parece conveniente comenzar por un ámbito más modesto, quizás en alguno de los asuntos donde ya existe buena cooperación. Más tarde, podría ampliarse según se considerara, pero el objetivo primario no es la amplitud, sino la profundidad. El ente supranacional en el que se delegue la soberanía será el Consejo, según lo establecido en el Art. 330 del TFUE; según el mismo artículo, la unanimidad estará constituida por los integrantes de la CR.

Puesto que se trata en última instancia de la comunitarización de la PESC, parece que los Estados que deberían formar el primer núcleo son los de tradición europeísta ${ }^{22}$. Existe, como decíamos antes, el riesgo de institucionalizar las diferencias con las visiones atlantista y neutral. Pero ya el Art. 328.1 advierte de que los Estados que participen en una CR deben fomentar la participación del mayor número posible de miembros, lo cual al fin y al cabo es el objetivo último que se persigue. Ya hemos visto cómo los Tratados contienen provisiones para garantizar el respeto a las posiciones atlantistas. En cuanto a las neutrales, son más difícilmente conciliables, porque por definición el neutralismo y la comunitarización se oponen entre sí. A lo mejor hay que aceptar que los países de tradición neutral no entren nunca en la verdadera PESC, o bien esperar que el tiempo y la influencia del grupo (además la creciente dificultad de mantener el aislamiento en el agitado panorama internacional actual y previsible, y la creciente irrelevancia de la neutralidad en un mundo multipolar ${ }^{23}$ ) vayan limando dicho carácter neutral hasta hacer entrar a esos países en el nivel en que la soberanía se encuentra delegada en el nivel supranacional, porque vean en ello más ventajas que inconvenientes.

Puesto que el objetivo es lograr el acuerdo más amplio posible, es de capital importancia la disposición a ceder. Conviene por lo tanto que los Es-

${ }^{22}$ Entre los cuales, por cierto, Francia es un socio poco fiable para este fin, puesto que, pese a su retórica europeísta, tiende a remolonear cuando se trata de ceder soberanía (Molina 2012)

${ }^{23}$ En el cual, por otra parte, pocos defenderán los intereses de los neutrales con más coincidencia que el resto de la UE. 
tados del núcleo inicial valoren más la consecución de un acuerdo que la prevalencia del propio punto de vista. Puesto que los Estados de mayor peso son en general más celosos de su propio punto de vista, podría darse el caso de que la mejor solución posible fuera que el núcleo incial estuviera formado por Estados medianos y pequeños. Si fuera el caso, conviene subrayar que la forja del más amplio consenso posible podría perfectamente compensar la falta de miembros de mucha entidad, siempre que la amplitud del consenso (y por tanto la entidad agregada de los Estados que se adhirieran) fuera significativa. Como etapa posterior, sería esperable convencer paulatinamente a los demás a medida que la iniciativa fuera dando sus frutos.

Es posible que eso no se consiga nunca para todos los países a la vez, pero eso tampoco es imprescindible para lograr la masa crítica que permita escapar a la irrelevancia de la UE en el exterior. Lo que sí está claro en todo caso es que si no se comienza el proceso por algún sitio, tampoco se conseguirá nunca comunitarización alguna, y no habrá pues masa crítica que evite la irrelevancia.

\subsection{La cooperación estructurada permanente (CEP)}

Esta posibilidad se creó teniendo en mente específicamente la PCSD. Está recogida en el Art. 42.6 del TUE, y se reserva a aquellos países que cumplan criterios más elevados de capacidades militares y que hayan suscrito compromisos más vinculantes en la materia para realizar las misiones más exigentes. El Art. 46 refiere al Protocolo sobre la $\mathrm{CEP}^{24}$, que establece una serie de condiciones que concretan lo anterior. En general incluyen la provisión de unidades de primera línea y rápidamente desplegables, y enumeran una serie de asuntos en que los Estados se comprometen a coordinarse, tales como la interoperabilidad, el carácter desplegable y, significativamente, el gasto en Defensa.

No ha habido aún intentos de avanzar por esa vía ni parece que vaya a haberlos en el futuro próximo. Después de todo, el cumplir criterios más elevados de capacidades implica necesariamente invertir más en Defensa (aparte de que lo consagre el Protocolo), cosa poco acorde con el signo de estos tiempos de crisis. Pero la herramienta existe y está disponible. ${ }^{25}$

Llegado el caso, la ventaja de la CEP es que no hay un número mínimo de países que deban ponerse de acuerdo para poder establecerla. Y, desde luego, que, como acicate para la mejora de las capacidades de la UE (cosa fundamental para lograr la autonomía, como hemos visto), es enormemente eficaz.

\section{EL PESO DE LA OPINIÓN PÚBLICA}

En relación con la legitimidad directa cuya importancia hemos visto (Dullien y Torreblanca 2012), y puesto que las transformaciones que estamos

24 Publicado en el Diario Oficial de la UE del 16 de diciembre de 2004.

25 Salvo que la capacidad de contribuir fuerzas rápidamente desplegables debía de poseerse para 2007. No parece lógico, en cualquier caso, que cambiar eso vaya a impedir poner en marcha el procedimiento si todo lo demás se cumple y hay voluntad. 
considerando son de gran calado, parece necesario que estén respaldadas por una parte muy mayoritaria de la población. El conjunto de estadísticas que se presenta a continuación ayudará a averiguar hasta qué punto las opiniones públicas son favorables a la progresión en la unión, en general, y en la PESC, en particular. Se ha decidido utilizar las estadísticas del Eurobarómetro por su fiabilidad, que se sustenta en el tamaño de las muestras y en la longitud de la mayor parte de las series estadísticas, así como en la coherencia de cada una de las series a través del tiempo.

El Eurobarómetro proporciona los siguientes datos sobre las opiniones y percepciones de la ciudadanía sobre el proceso de construcción europea. Los datos están referidos a la UE-2 $27^{26}$.

\subsection{Una política exterior común a los 27 miembros de la UE}

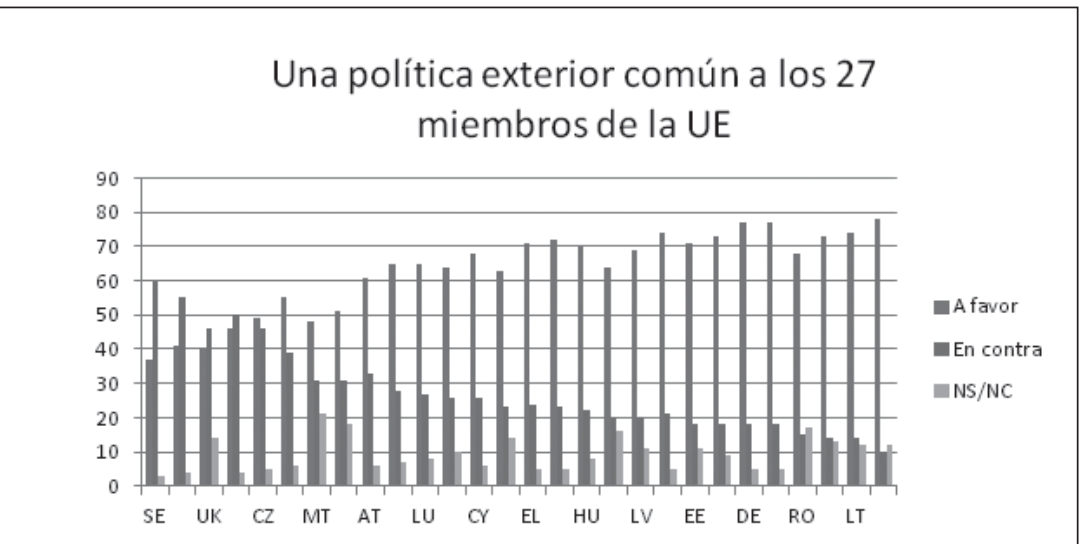

La media europea a favor es relativamente elevada, lo cual sugiere que la idea sería aceptable para la mayoría de europeos.

Se observa además que en la mayor parte de los países la proporción de los que están a favor es bastante similar a la media europea. Los países en los que esto no se cumple se pueden dividir en dos grupos: aquéllos en que los que están en contra superan a los que están a favor (Suecia, Finlandia, el Reino Unido y Dinamarca), y aquéllos en que la proporción a favor es sensiblemente menor que la media, aunque supera a la proporción en contra (la República Checa, los Países Bajos, Malta e Irlanda).

En cuanto a la proporción entre los que están a favor y los que están en contra, ordenada de mayor a menor, queda como sigue:

${ }^{26}$ Salvo que se especifique otra cosa, todos los datos que se reflejan en este trabajo están extraídos del último Eurobarómetro estándar publicado ( $\mathrm{N}^{\circ} 78$, otoño 2012). Los gráficos, salvo que se indique otra cosa, son de elaboración propia. 


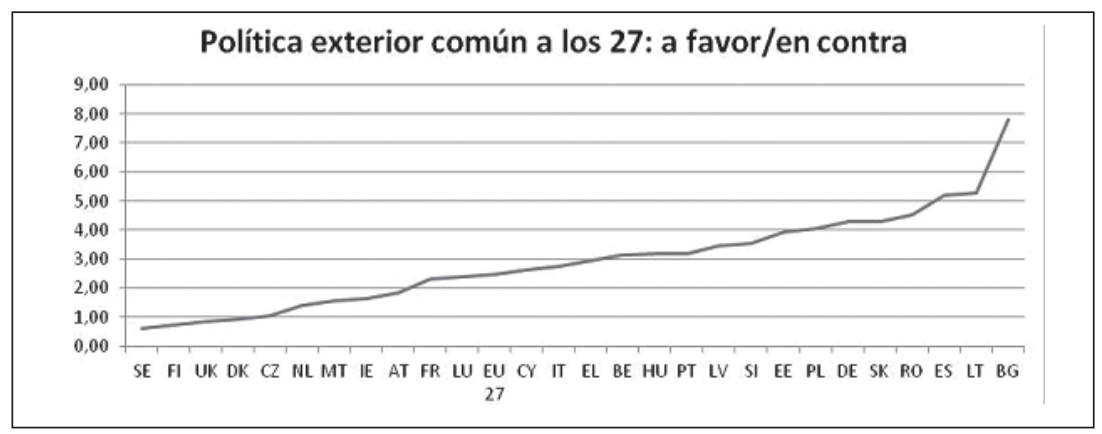

La media europea está en 2,46. Los que no superan los 3 a favor por cada en contra son $^{27}$ : Suecia, Finlandia, el Reino Unido, Dinamarca, la República Checa, los Países Bajos, Malta, Irlanda, Austria, Francia, Luxemburgo, Chipre, Italia y Grecia.

La mayoría de los que hemos citado en el gráfico anterior se encuentran también en éste, y en todos ellos se da alguna característica que dificulta la integración europea. Nótese que algunos pueden participar de varias de ellas:

- Países de cultura estratégica intervencionista y asertiva muy marcada, y por lo tanto más celosos de su soberanía (el Reino Unido, Francia, y los Países Bajos).

- Países de tradición atlantista (el Reino Unido, Dinamarca, los Países Bajos e Italia).

- Países de tradición neutral (Suecia, Finlandia, Irlanda y Austria).

- Países donde la integración europea en su conjunto tiene un apoyo relativamente escaso (el Reino Unido, Dinamarca).

\subsection{Una política de seguridad y defensa común a los 27}

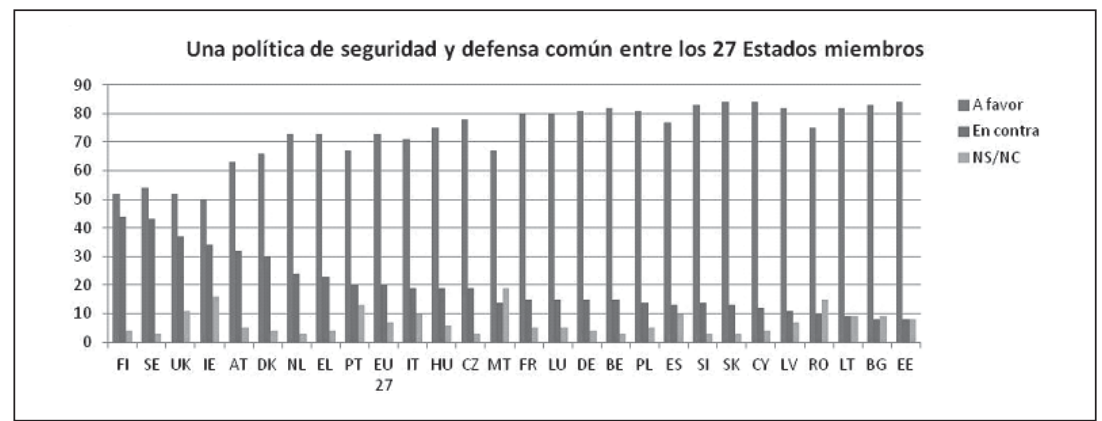

${ }^{27}$ Hemos elegido esta proporción porque la mayoría de los a favor que representa es suficientemente amplia como para augurar un adecuado respaldo público al proceso. 
En todos los países la proporción de a favor supera a la proporción en contra. Están sensiblemente por encima de la media de en contra: Finlandia, Suecia, el Reino Unido, Irlanda, Austria y Dinamarca. guiente:

En cuanto a la proporción entre a favor y en contra, la tabla es la si

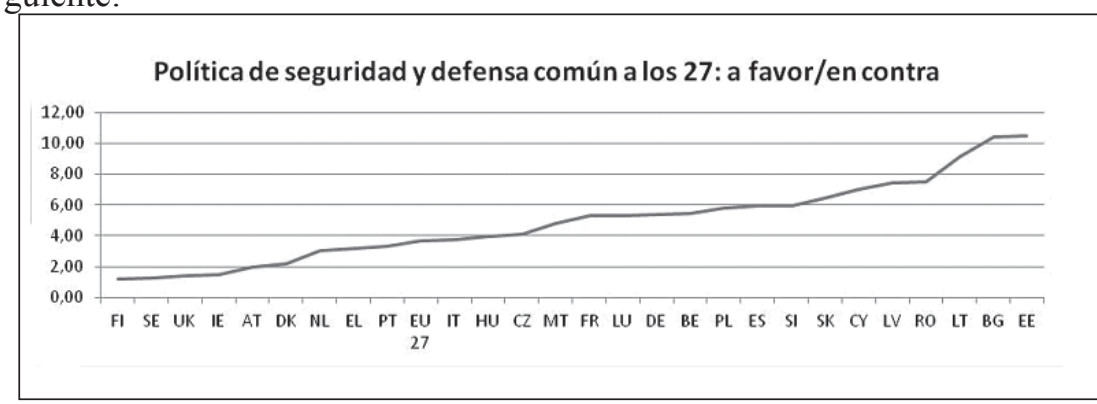

Por debajo de la misma proporción de tres a favor por cada en contra están Finlandia, Suecia, el Reino Unido, Irlanda, Austria, Dinamarca y, justo por encima, los Países Bajos. Se observan dos cosas:

- una coincidencia significativa en los países menos entusiastas con la pregunta anterior.

- La proposición suscita todavía mayor aceptación que la anterior.

\subsection{La UE debería constituirse en una federación de Estados-Nación}

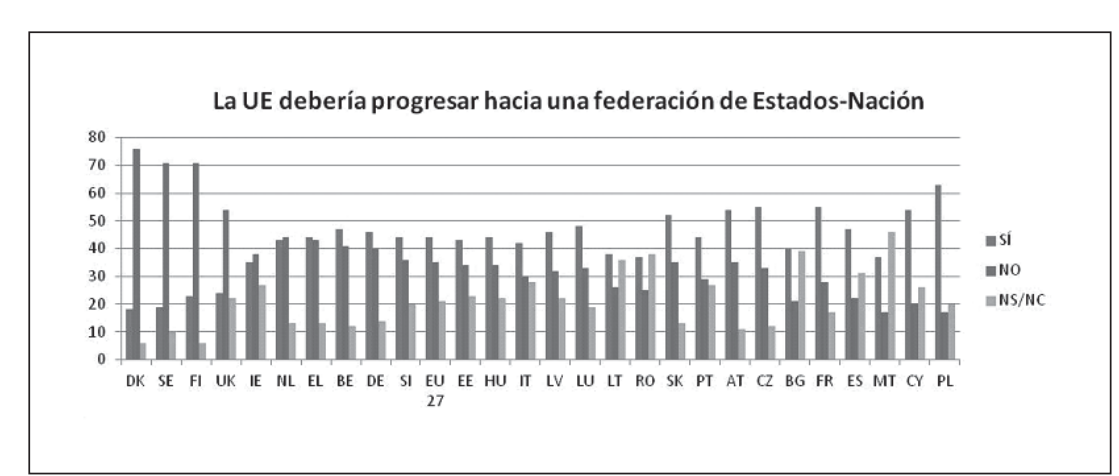


La constatación inmediata es que no existe un respaldo público claro para este proceso si se plantea en términos generales. Se recogen además tasas muy altas de No sabe, no contesta.

\subsection{Con qué velocidad está sucediendo la integración europea ${ }^{28}$,}

Pregunta: En su opinión, ¿cuál es la velocidad actual de la construcción europea? Mire por favor estas figuras. La número 1 está parada, la $n^{\circ} 7$ corre tan rápido como puede. Elija la que mejor represente su opinión de la velocidad actual de la construcción europea.

En el gráfico siguiente, hemos agrupado como lento las respuestas 1 a 3 y la mitad de la 4, y como rápido las 5 a 7 y la mitad de la 4.

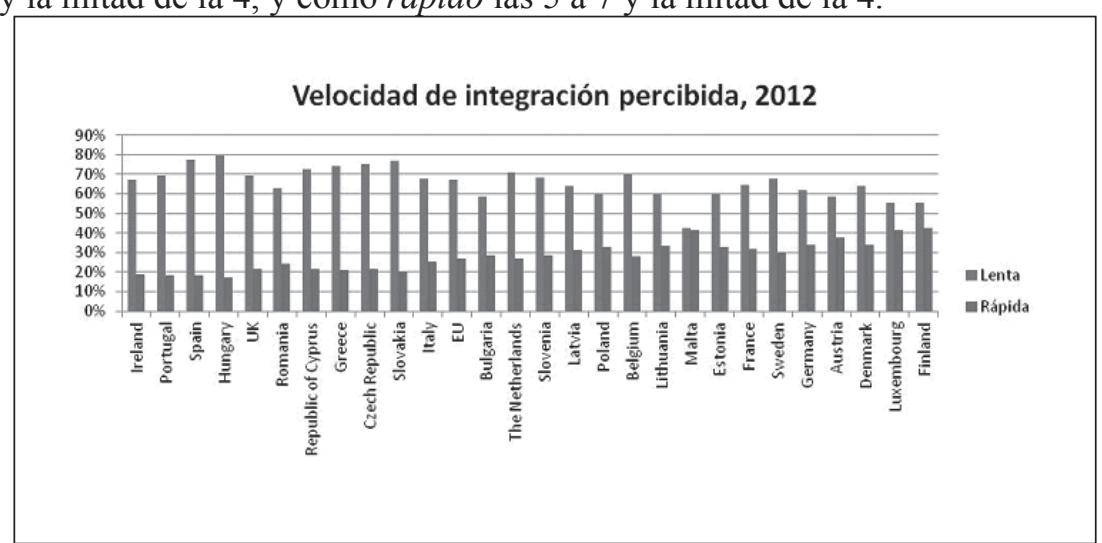

Se puede ver que en general la velocidad percibida es apreciablemente más lenta que rápida.

La siguiente gráfica deriva de los valores utilizados para la anterior, y refleja el orden de los países según un índice calculado de la siguiente manera: Índice $=100 *(1 *(\%$ respuesta 1$)+2 *(\%$ respuesta 2$)+(\ldots)+7(\%$ respuesta 7)-100. El índice es lineal, de modo que un 100\% de respuestas 1 («no avanza») daría un índice 0 , un $100 \%$ de respuestas 7 («avanza a máxima velocidad») daría un índice 600, y un $100 \%$ de respuestas 4 (en el punto medio) daría un índice 300.

${ }^{28}$ Las preguntas 9.4. y 9.5. no proceden del Eurobarómetro estándar, sino del sistema de búsqueda interactiva.

${ }^{29}$ Las respuestas a esta pregunta y a la siguiente datan de mayo de 2012, que es la última vez que se hicieron. 


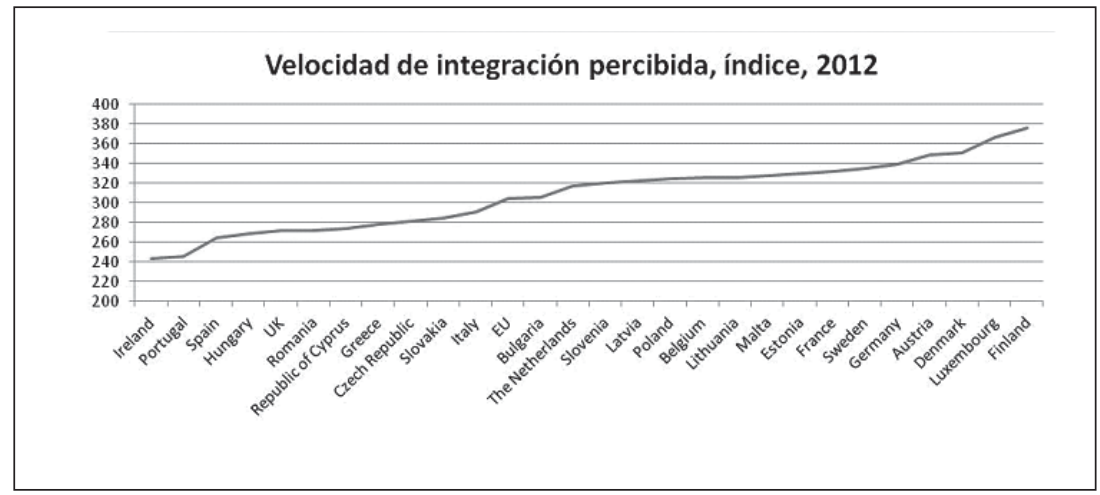

La percepción de la velocidad de la integración es media (índice 300), y está muy progresivamente repartida. No se observa correlación entre la percepción de la velocidad de integración y las estadísticas anteriores.

\subsection{Con qué velocidad desearía Vd. que se produjera la integración eu- ropea}

Pregunta: ¿Y cuál representa mejor la velocidad que Vd. desearía? La mecánica es la misma que en la pregunta anterior.

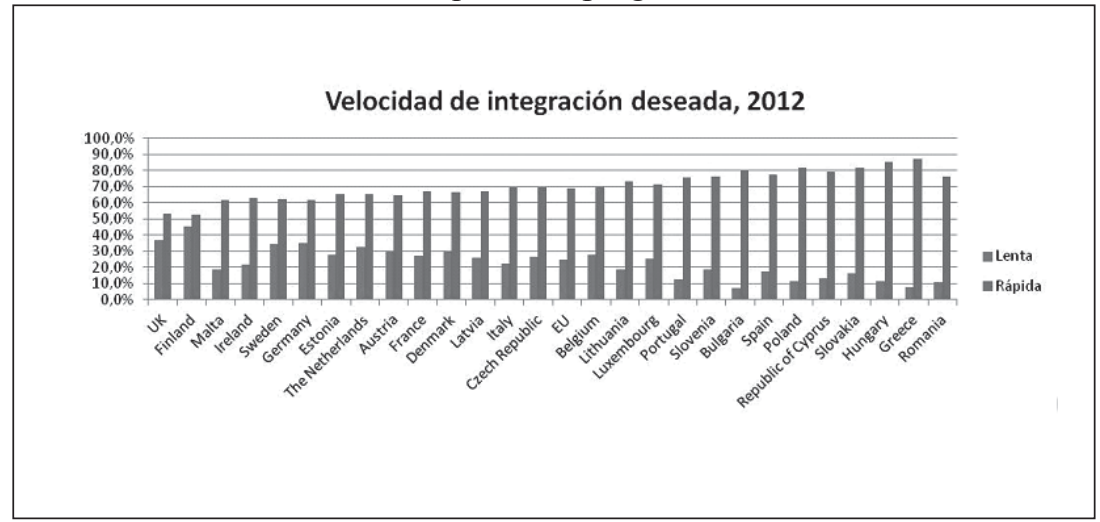

Se puede ver que, curiosamente, la velocidad deseada es más rápida que lenta en todos los países, incluidos los que en las preguntas anteriores se mostraban mayoritariamente reticentes a la profundización en la unión. Esto es tanto más inesperado cuanto que no hay una acumulación de porcentaje alto en la velocidad 1 (no avanzar), a pesar de que no era posible responder que se prefería retroceder en la integración. Se podría pensar si la pregunta sólo iba dirigida a quien hubiera respondido antes que sí quería más integra- 
ción, pero la lectura del último Eurobarómetro en que aparecía esta pregunta (el 77, primavera de 2012) muestra que no era así.

El índice según términos equivalentes al de la pregunta anterior, queda como sigue:

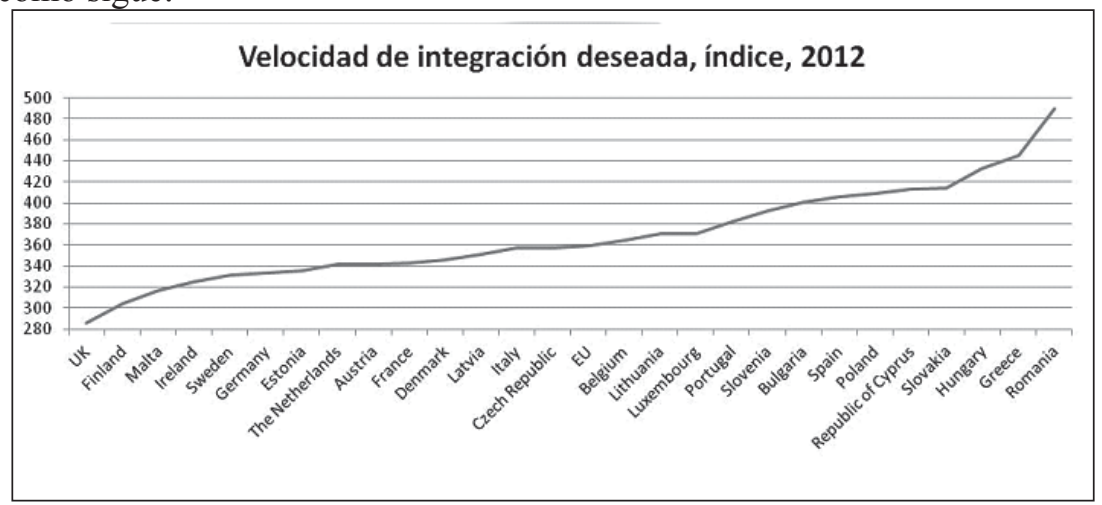

El índice de velocidad deseada para el conjunto de la UE está en 359, que corresponde a una velocidad del $60 \%$ de la máxima posible. Sólo en un país (el Reino Unido) la velocidad deseada está ligeramente por debajo de la mitad de la máxima posible.

Se observa una cierta correlación (imperfecta) entre esta estadística y las primeras: el Reino Unido, Finlandia, Malta, Irlanda, Suecia, los Países Bajos, Austria, Dinamarca y Francia están por debajo de la media, lo cual concuerda con las primeras estadísticas. Pero también están por debajo de la media Alemania y Estonia, que en las primeras estadísticas estaban significativamente por encima.

Calculando para cada país la relación entre los índices de la velocidad deseada y la percibida ${ }^{30}$, resulta lo siguiente:

${ }^{30}$ Es una simplificación excesiva para poder sacar datos exactos, pero sí permite inferencias «grosso modo», que es lo que se pretende. 


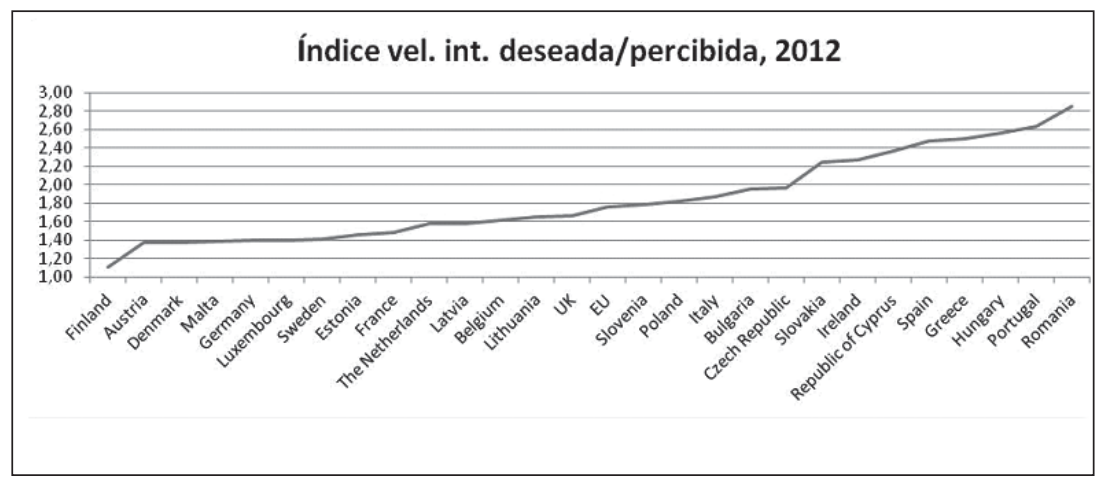

Se constata que:

- En todos los casos la velocidad deseada es mayor que la percibida.

- Solamente en Finlandia la velocidad percibida es sensiblemente igual a la deseada.

- El índice de la media europea de la velocidad deseada es el doble del de la percibida.

- No se observa correlación clara entre esta curva y las anteriores.

- Contemplando las tres curvas en conjunto, se observa la siguiente correlación: los países con problemas económicos significativos perciben en general una velocidad de integración lenta, la desean rápida y tienden por tanto a la parte alta de la última gráfica. En los que tienen las cuentas saneadas sucede, respectivamente, lo contrario en cada una de las curvas.

\subsection{Cuáles son los dos mayores problemas a los que se enfrenta la UE en la actualidad}

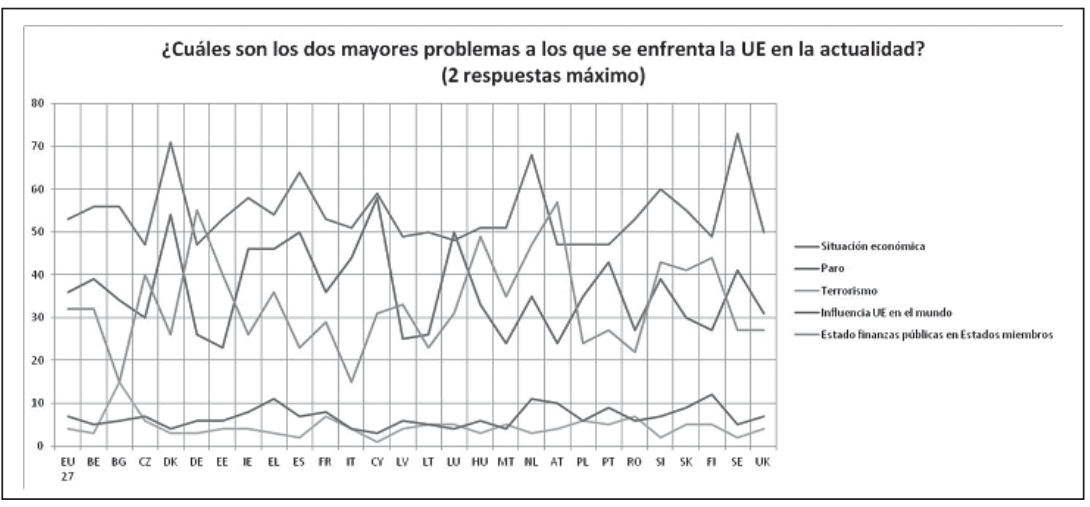


La única razón de incluir esta gráfica (en la que no se reflejan todas las respuestas posibles) es mostrar que los objetivos económicos son los que en mayor proporción demanda a la UE la ciudadanía.

\subsection{Me siento más seguro porque mi país es miembro de la UE}

Esta pregunta es una buena indicación de hasta qué punto la UE se percibe como una alternativa eficaz a la OTAN para proporcionar seguridad a sus miembros.

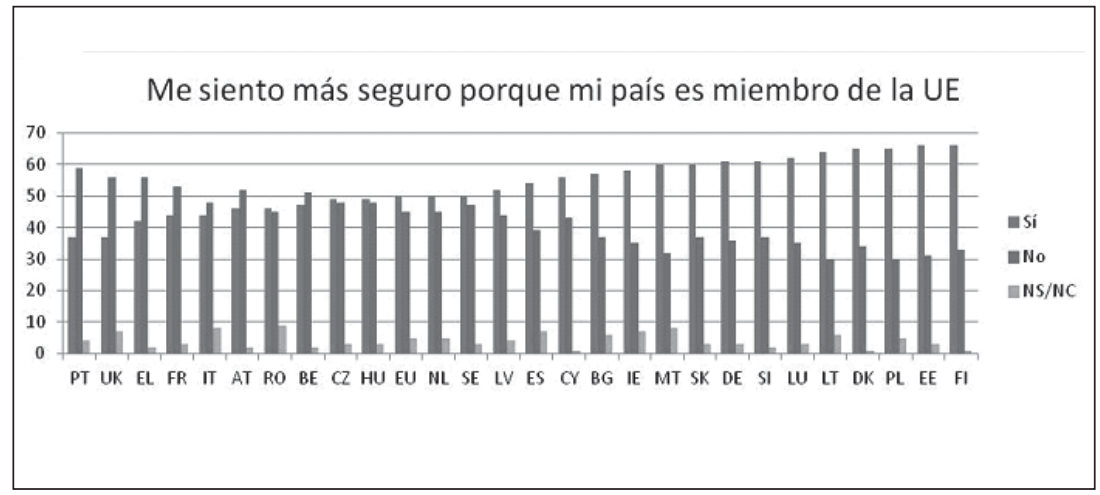

La media europea está prácticamente igualada entre el «sí» y el «no». Lo cual quiere decir que una parte significativa de la población ve a la UE como un proveedor de seguridad fiable.

Se observa correlación imperfecta entre el «no» y el gasto en Defensa. El Reino Unido, Francia y Grecia están en la parte alta de la tabla. También está Portugal, presumiblemente en virtud de su secular alianza con el Reino Unido.

No se observa correlación entre las respuestas en un sentido o en otro y:

- el grado de atlantismo. Portugal, el Reino Unido e Italia están en un extremo de la tabla, pero los Países Bajos están en la parte media y Dinamarca en el otro. Los antiguos países de la órbita soviética están repartidos por toda la tabla.

- el grado de asertividad de la política exterior. El Reino Unido y Francia están en un extremo, y Alemania cerca del otro, pero Italia está cerca de los primeros, y España en la parte media.

- el grado de neutralidad. Austria está en un extremo, Suecia en la parte media, Irlanda tiende a la parte baja y Finlandia es el último. 


\subsection{Conclusiones generales de las estadísticas}

El apoyo al avance en la consecución de una política exterior y una política de seguridad y defensa comunes es muy elevado, salvo en algunos países concretos.

No existe respaldo público claro a la progresión hacia una federación de Estados-Nación. En cuatro países los que piensan que no se debe progresar en ese sentido superan a los que opinan que sí. Es la única pregunta de las consideradas que recoge una proporción significativa de «No sabe, no contesta».

No obstante la estadística anterior, en todos los países es mayoritaria la opinión de que se debe avanzar en la integración europea. Se percibe una velocidad de integración media, y en todos los países se considera deseable una velocidad igual o mayor.

Una parte significativa de la opinión pública ve ya a la UE como un proveedor de seguridad relativamente fiable.

En cuanto a las variaciones entre países, y con la excepción de las preguntas sobre la progresión hacia una federación de Estados-Nación y sobre los dos problemas más importantes a que se enfrenta la UE, se observa en general una desviación típica moderada, una distribución uniforme entre los valores máximo y mínimo y una coherencia en el sentido de las respuestas dominantes en cada país a cada una de las preguntas. Con eso se tiene una indicación bastante buena de qué ciudadanías son más favorables a la integración.

\section{CONCLUSIONES}

La parte de Occidente en la actividad mundial disminuye de manera lenta pero perceptible, y paralelamente lo hace su influencia en el sistema internacional. No parece que esa tendencia vaya a hacer otra cosa que acentuarse en el futuro. Eso es especialmente cierto en el caso de Europa, cuyas naciones son además demasiado pequeñas para influir en solitario en todos los asuntos que quisieran. La solución para recuperar influencia pasa por profundizar en la unión política en el seno de la UE, cuyo objetivo último declarado es la delegación de soberanía en un ente supranacional.

No se debe perder de vista que nada en este proceso debe ser contra los EE.UU, ni éstos deben ver maniobras contra ellos donde no las haya. En un mundo cuyo centro se aleja de Occidente, la UE y los EE.UU. están condenados a complementarse, y cada uno necesita que el otro sea autónomo en el mayor grado posible.

La autonomía con que Europa podría ejercer su política exterior con respecto a los EE.UU., la inversión en Defensa y la consecución de capacidades militares son tres magnitudes directamente proporcionales entre sí y que se refuerzan mutuamente. Por lo tanto, la persecución de la primera implica 
aceptar la necesidad de las otras dos, y a la vez puede actuar de revulsivo para perseguirlas.

Por complejidad y por calado de las renuncias necesarias, no es realista llegar a la delegación de soberanía mediante un proceso que implique a todos los miembros de la UE a la vez.

La alternativa es intentarlo con un grupo inicial, pero teniendo siempre presente que el fin último es conseguir la adhesión, si no de todos, sí de la mayoría de países. Primeramente porque así lo manda el propio TFUE (Art. 328.1), pero sobre todo porque es la suma del poder agregado de los países que participen en esa comunitarización de la PESC lo que dará la medida de la influencia que el grupo va a tener. El grupo inicial debería estar integrado por países de tradición europeísta y de cultura estratégica poco intervencionista, que se prestan mejor a esta iniciativa.

Ya existen herramientas que facilitarían el avance hacia esa delegación de soberanía, que en lo tocante a la PESC parece tener respaldo público claro en un buen número de países: la cooperación reforzada y la cooperación estructurada permanente. La primera parece la más prometedora para avanzar en el plano político, pero la segunda es una herramienta muy potente para reforzar el punto débil de la PESC: la escasez de potencia militar.

Sin embargo, el momento actual de crisis parece menos propicio que uno de relativa abundancia, puesto que la prioridad de la opinión pública está volcada sobre los asuntos socioeconómicos, y sería difícil explicar un giro copernicano en otro ámbito sin haber resuelto primero el prioritario. Otra razón para esperar a una época de mayor disponibilidad presupuestaria es que la autonomía en cuestiones de seguridad y Defensa pasa por gastar en ello significativamente más de lo que la mayoría de Europa viene gastando.

\section{BIBLIOGRAFÍA}

Alecu De Flers, N., The provisions on CFSP and CSDP in the Lisbon Reform Treaty: Stumbling blocks or milestones? Documento de investigación, Jerusalén: International Law Forum, Hebrew University, 2008.

ChUter, D., Humanity's soldier: France and international security, 19192001. Providence (EE.UU.): Berghahn Books, 1996.

Dullien, S., y Torreblanca, I., What is political union? Policy Brief, Londres (Reino Unido): European Council on Foreign Relations, 2012.

Economou, E.M.L., y Metaxas, T., «EU and US security policy from the Cold War era to the 21st century: The institutional evolution of CFSP and the factors that determine the American military supremacy», $\mathrm{Mu}$ nich Personal RePEc Archive, 2011.

FABRY, E., (dir.). Think global act european IV: Thinking strategically about the EU external action. París: Notre Europe - Jacques Delors Institute, 2013. 
García Pérez, R., Política de Seguridad y Defensa de la Unión Europea. Madrid: Universidad Nacional de Educación a Distancia, 2003.

Giegerich, B. European Security and Strategic Culture. Baden-Baden (Alemania): Nomos, 2006.

Giegerich, B., y Gross, E., «Squaring the circle? Leadership and legitimacy in European Security and Defence Cooperation», International Politics 43 (2006): 500-509.

HiLl, C., «The capability-expectations gap, or conceptualising Europe's international role», Journal of Common Market Studies 31, 1993: 305-28.

Hunter, R., The European Security and Defense Policy: : NATO's Companion - or Competitor? Santa Mónica (EE.UU.): RAND Corporation, 2002.

Kennedy, P., The rise and fall of the great powers. Nueva York: Vintage Books, 1988.

Keohane, R., After Hegemony: Cooperation and discord in the world political economy. Princeton, EE.UU.: Princeton University Press, 1984.

- International Institutions And State Power: Essays in International Relations Theory. Boulder (EE.UU.): Worldview Press, 1989.

Molina, I., «¿Querer es poder? ¿Qué significan las dos velocidades que propone Merkel para avanzar en la integración europea?», Real Instituto Elcano. 8 de junio de 2012.http://www.realinstitutoelcano.org/wps/portal/ rielcano/Imprimir?WCM_GLOBAL_CONTEXT=/elcano/Elcano_es/ Zonas_es/Comentario_Molina_Europa_integracion_dosvelocidades (último acceso: 26 de febrero de 2013).

Moravcsik, A., The Choice for Europe: Social Purpose and State Power from Messina to Maastricht. Ithaca (EE.UU.): Cornell University Press, 1998.

Priego, A., Presente y futuro de la acción exterior de la UE. Documento marco, Madrid: Instituto Español de Estudios Estratégicos, 2013.

Schmid, V., «Democracy and Legitimacy in the European Union Revisited: Input, Output and "Throughput"», Political Studies 61, n 1 (2013): 2-22.

SiмÓn, L., No might, no right: Europeans must re-discover military power. Documento de investigación, Madrid: Real Instituto Elcano, 2013.

Techau, J., «It's the military, stupid!» 13 de mayo de 2013. carnegieeurope. $\mathrm{eu} /$ strategiceurope/?fa=51040 (último acceso: 26 de febrero de 2013).

ToJE, A., «The European Union as a small power», Journal of Common Market Studies 49, $\mathrm{n}^{\circ} 1$ (2011): 43-60.

UnIÓN EUROPEA. «A secure Europe in a better world: European Security Strategy.» Bruselas, 2003.

- Eurobarometer Interactive Search System. http://ec.europa.eu/public_opinion/cf/step1.cfm (último acceso: 21 de mayo de 2013). 
- «Eurobarómetro estándar $\mathrm{n}^{\mathrm{o}} 78$ (otoño 2012), anexo.» 2012. http:// ec.europa.eu/public_opinion/archives/eb/eb78/eb78_anx_en.pdf (último acceso: 2013 de abril de 13).

- «Protocol on Permanent Structured Cooperation established by Article I-41(6) and Article III-312 of the Constitution.» Official Journal of the European Union. 16 de 12 de 2004. C310/364-366.

- «Tratado de la Unión Europea (versión consolidada).» Diario Oficial de la Unión Europea. 30 de marzo de 2010. C83 / 13 - 45.

- «Tratado del Funcionamiento de la Unión Europea.» Diario Oficial de la Unión Europea. 9 de mayo de 2008. C115/47-199.

VILANOVA, P., y BAQuÉs, J., (coord.). La crisis del vínculo transatlántico: ¿coyuntural o estructural? Cizur Menor (Navarra): Aranzadi, 2008.

WAGNER, W., «Why the EU's common foreign and security policy will remain intergovernmental: a rationalist institutional choice analysis of European crisis management policy», Journal of European Public Policy, 10:4, 2003: 576-595.

Wallace, H., y Wallace, W., The institutional setting: five variations of a theme. Policy-making in the European Union. Oxford (Reino Unido): Oxford University Press, 2000.

Wendt, A., Social theory of international politics. Nueva York: Cambridge University Press, 1999.

RESUMEN: El motor fundamental del proyecto europeo ha sido la integración política como vía para mantener y desarrollar la posición y proyección de los países europeos en el plano internacional de las naciones y facilitar objetivos políticos, económicos y estratégicos a corto, medio y largo plazo. La trayectoria que ofrece hoy la política mundial, en el fondo, muestra que la profundización en el ideal de unión política es el único medio para que, en el futuro, Europa siga teniendo un rol de primer nivel en el marco internacional. Este trabajo analiza esta cuestión y, además, en qué grado y forma la Politica Exterior y de Seguridad Común (The Common Foreign and Security Policy) y la Politica Común de Seguridad y Defensa (Common Security and Defence Policy) suponen instrumentos necesarios en este sentido.

PalabRaS ClaVE: Unión Europea, unión politica, Política Exterior y de Seguridad Común, Política Común de Seguridad y Defensa.

TITLE: European Union: To a really common Foreign and Security Policy.

ABSTRACT: The principal motor of the european project has been the political integration as a way to keep und improve the european countries position and its projection in the international scene and to make possible political, economic and strategic objectives in short, medium und longterm. The path offered by the global policy in the present situation, at bottom, shows that the strengthening in the ideal of a political union is the only way so that Europe in the future can carry on keeping a good rol in the international scene. This article analyses this question and also in 
which degree and form the Common Foreign and Security Policy and the Common Security and Defence Policy are necessary instruments in this sense.

KEYWordS: European Union, political union, Common Foreign and Security Policy, Common Security and Defence Policy.

Recibido: 02.09.2013

Aceptado: 16.09.2013 